\title{
ASO Visual Abstract: Prognosis for Poorly Differentiated High- Grade Rectal Neuroendocrine Carcinomas
}

\author{
Derek J. Erstad, MD (1) , Arvind Dasari, MD, Melissa W. Taggart, MD, Harmeet Kaur, MD, \\ Tsuyoshi Konishi, MD, Brian K. Bednarski, MD, and George J. Chang, MD
}

The University of Texas MD Anderson Cancer Center, Houston, TX

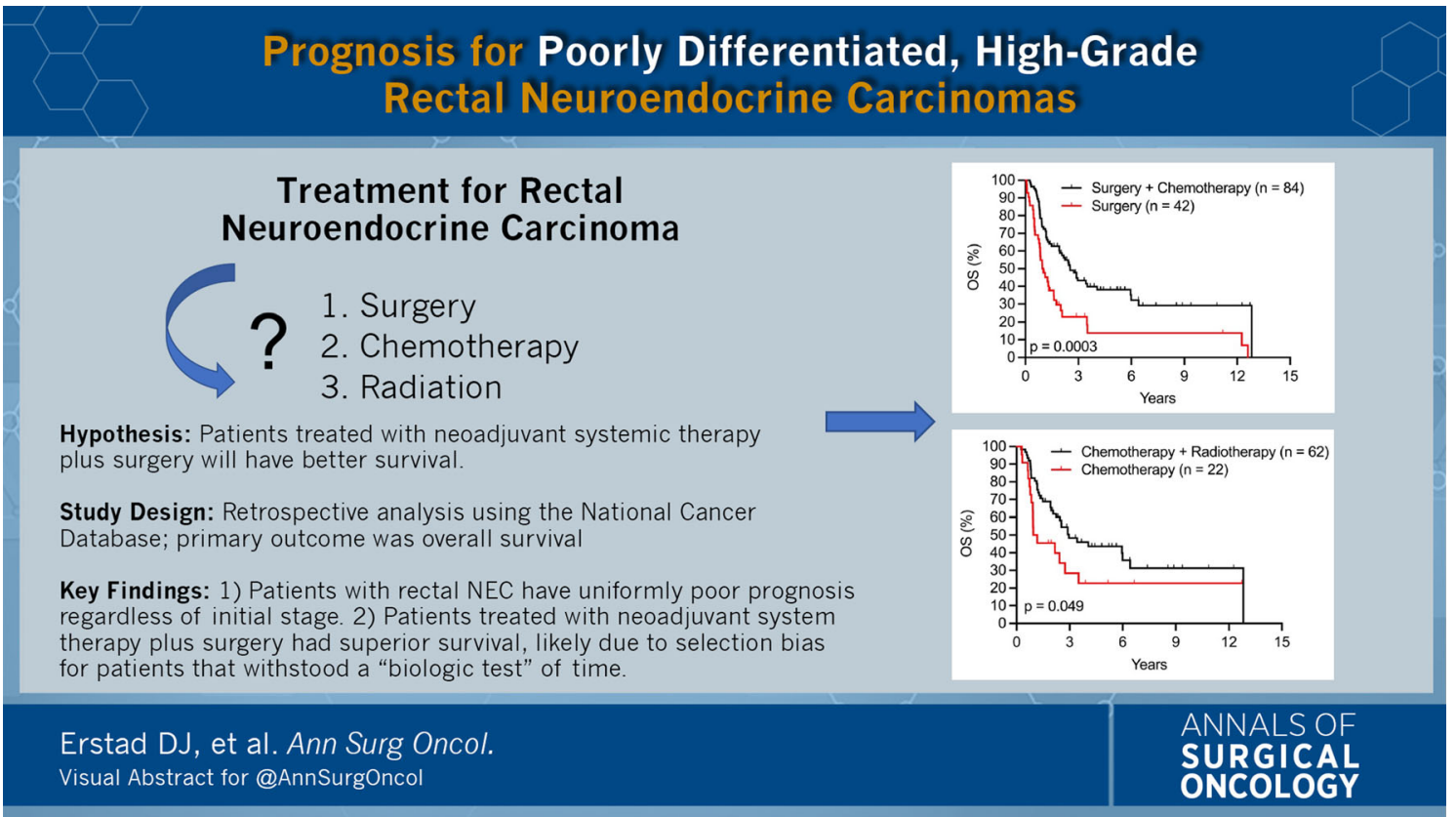

Rectal neuroendocrine carcinomas (rNECs) are rare, aggressive malignancies. Treatment recommendations include surgical resection and chemotherapy for appropriate candidates. In this descriptive analysis of 805 patients with rNEC (http://doi.org/10.1245/s10434-021-11016-8 ), we observed dismal prognosis, including after radical resection, suggesting that operative candidates should be judiciously chosen. Systemic chemotherapy was associated with improved outcome.

(C) Society of Surgical Oncology 2022

G. J. Chang, MD

e-mail: gchang@mdanderson.org
AUTHOR CONTRIBUTIONS DJE performed data acquisition, data analysis and interpretation, and manuscript construction. AD, MWT, HM, and GJC contributed to manuscript creation.

FUNDING There are no financial relationships related to the design or execution of this study.

DISCLOSURE There are no conflicts of interest related to the design or execution of this study.

Publisher's Note Springer Nature remains neutral with regard to jurisdictional claims in published maps and institutional affiliations. 